\title{
Space-based technologies and high performance computing in support of environmental sustainability in developing countries
}

\author{
Gilbert L. Rochon
}

Published online: 21 August 2009

(C) Springer-Verlag 2009

Inspired by recent service on the User Working Group for NASA's Socio-Economic Data Applications Center (SEDAC), the Science Review Panel for the Arctic Region Supercomputer Center, the Technology Advisory Committee for South Africa's Center for High Performance Computing and participation in the NATO Pilot Study on Clean Products and Processes over the past four years, our distributed interdisciplinary research collaborators intensified our efforts to address some of the fundamental issues with respect to societal sustainability. We particularly focused on highly vulnerable communities, at risk for an array of immediate and long-term biogenic and anthropogenic disasters. Specifically, we sought to address the question: "How should state-of-the-science computational capabilities and earth observing satellites be optimally placed in the service of environmental sustainability and sustainable development?"

In the on-going process of examining this issue, it has been encouraging to observe the technological progress that has recently occurred within Latin America, Asia and Africa. CONAE http://www.conae.gov.ar/eng/aplicaciones/ salud_new.html, the Argentine Space Agency's SAC-C satellite has been operational since 2000 and its successor, Aquarius (SAC-D) will be launched in 2010; while SABIA (SAC-E), the Argentine-Brazilian Satellite for Information on Food, Water and the Environment, ALSAT-2 (SAC-F) and SAOCOM 1-A, with microwave radar and a thermal infrared camera, are each currently under production.

\section{G. L. Rochon $(\square)$}

Purdue Terrestrial Observatory (PTO), Information Technology at Purdue (ITaP), Rosen Center for Advanced Computing (RCAC), Purdue University, 203 Martin Jischke Drive, Mann Hall 160, West Lafayette, IN 47907, USA

e-mail: rochon@purdue.edu
Brazil's other collaboration with China, the ChineseBrazilian Earth Resources Satellite (CBERS) has been generously offered without licensure fees to developing countries. China, as well, freely offers its Fung Yun 1D MVISR globally to receiving stations. Robust earth observing satellite launch schedules are apparent in China, India, Japan, Korea, Taiwan and Thailand. African engagement in satellite remote sensing has been actively promoted by the African Association for Remote Sensing of Environment (AARSE) and by the 2009 IEEE International Geo-science \& Remote Sensing Symposium (IGARSS) held in Cape Town, South Africa.

As a follow-on to the NATO Committee on the Challenges to Modern Society's Pilot Study on Clean Products $\&$ Processes, the NATO Science for Peace Program has awarded funding to establish the Kamal Ewida Earth Observatory http://www.itap.purdue.edu/pto/NATO_KEEO/ index_en.html, which will include real-time satellite ground stations in Egypt at Cairo University and Al Azhar University, primarily for early warning and mitigation of disasters, including storms, flooding and epidemics, through identifying and monitoring infectious disease vector habitat, as well as for facilitating natural resource management. This initiative is in collaboration with the Kandilli Observatory and Earthquake Research Institute at Boğaziçi University in Istanbul, Turkey and with the Purdue Terrestrial Observatory at Purdue University's Rosen Center for Advanced Computing in West Lafayette, Indiana, USA. Analysis of the real-time satellite data will benefit from a recently installed IBM Blue Gene L Supercomputer at Egypt's National Authority for Remote Sensing \& Space Sciences (NARSS), which has the capability to produce data products in near-real-time, as input to decision support for time-critical events. The other civilian supercomputer facility on the African continent is at South 
Africa's Center for High Performance Computing (CHPC) in Cape Town, which has installed an IBM Blue Gene P and a Sun Microsystems quad-core cluster. These capabilities, in combination with earth observing satellites from South Africa, Nigeria, Algeria and Morocco are harbingers of remote sensing's potential role as an equal opportunity technology, in that such satellites provide the same spatial, spectral and temporal resolution for the developing countries as is the case for the highly industrialized countries.

Geo-referencing satellite data and pinpointing areas at risk for environmental degradation, disaster vulnerability, epidemics or epizootics have been significantly enhanced by the critical redundancy of geo-positioning satellite constellations, including Beidou (Compass) from China, Galileo from Europe, GLONASS from Russia and the Global Positioning System (GPS) from the USA.

Notwithstanding the technological progress that has been made in some sectors, the challenges facing Africa, Asia and Latin America are formidable. Southern Africa's alarmingly high prevalence of HIV/AIDS has not sufficiently motivated the donor community to invest in low cost, battery operated portable CD4 T cell testing devices, which could dramatically increase the access to such diagnostics, would thereby enable eligibility for antiretroviral medication and facilitate monitoring throughout the treatment regimen for HIV/AIDS http://www.cytometry forlife.org/. The regional impact of climate change within the African Sahel could also continue to accelerate the southern migration of the African monsoon season, thereby imperiling food production and increasing the potential for human population migrations http://www.ciesin.org/.

Poverty, as a significant correlate with disaster vulnerability, infant mortality, malnutrition and infection, has also been shown to correlate with unsustainable natural resource utilization. Enlightened environmental policy must simultaneously address alleviating the impoverishment of small farmers in the Amazon and the protection of fragile tropical rainforest ecosystems. The capability exists to deploy state-of-the-science space-based remote sensing, airborne sensors, in situ detection and high performance computational resources in the service of sustainable and equitable development and environmental sustainability. To accomplish such objectives will require investment in spatial/temporal data infrastructure that will support broadband transmissions for rapid response to disasters, for planning support throughout the disaster life cycle (i.e. from vulnerability assessment and early warning through post-disaster reclamation), for telemedicine, for prudent natural resource management and for distance learning. It will also require re-investment in the higher education and research infrastructure within the developing countries.

Ultimately, the efficacy of sophisticated decision support mechanisms, designed to enable political leadership to make timely, wise, environmentally sound and inter-generationally humane decisions, within an information rich environment, is predicated upon the political will and commitment to serve the best interests of all the people, notwithstanding their socio-economic status, their gender or their ethnic, tribal, linguistic or religious affiliations. Inculcating such values within the training of scientists, engineers, lawyers, diplomats and politicians is the paramount challenge for academicians.

\section{Author Biography}

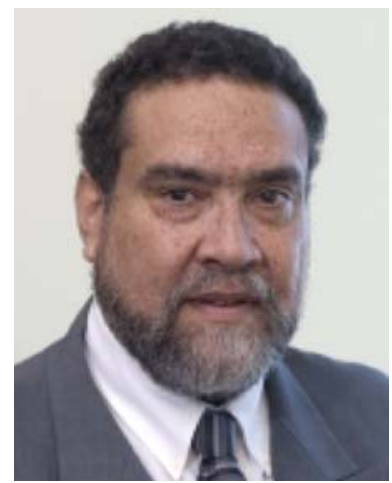

Gilbert L. Rochon, since 2002, is the Associate Vice President for Collaborative Research at Purdue University-Information Technology. Dr. Gilbert Rochon's portfolio includes service as Director, Purdue Terrestrial Observatory, Chief Scientist for the Rosen Center for Advanced Computing and Project Director for a NATO Science for Peace grant. He holds a Ph.D. from MIT in Urban and Regional Planning, a Master of Public Health degree from Yale University and a B.A. from Xavier University in New Orleans. 